\title{
URBAN AIR QUALITY ASSESSMENT METHOD BASED ON GIS TECHNOLOGY
}

\author{
JIA, Q. \\ North China University of Water Resources and Electric Power, Zhengzhou 450000, China \\ Henan Engineering Research Center of Water Pollution and Soil Damage Remediation, \\ Zhengzhou 450000, China \\ Henan Key Laboratory of Water Environment Simulation and Treatment, Zhengzhou 450000, \\ China \\ e-mail: jiamoney@126.com; phone: +86-176-0371-6888 \\ (Received $3^{\text {rd }}$ Apr 2019; accepted $17^{\text {th }}$ May 2019)
}

\begin{abstract}
The environmental impact of air pollutants emitted by energy consumption is becoming more and more serious. Air quality monitoring and evaluation is an important method to study the formation characteristics of regional air pollution, as well as an important means of comprehensive control and measurement of regional air pollution. In this paper, the emission list of Volatile Organic Compounds (VOCs) pollutants is established based on GIS technology, and the atmospheric diffusion of VOCs pollutants with five concerns in Shijiazhuang City is simulated by using AERMOD system model. The results show that the main industrial emission sources of VOCs come from steel, casting and cement industries, the flowing sources mainly come from diesel motor vehicles, and the surface sources come from vegetation and building ornaments. The AERMOD model has good applicability to the simulation of VOCs emissions. This paper gives full play to the spatial analysis ability of GIS technology and makes visual analysis of the evaluation results so as to provide decision-making basis for air quality prediction. Keywords: environment, air quality, atmospheric pollution, GIS technology, VOCs, AERMOD model
\end{abstract}

\section{Introduction}

In recent years, with the rapid development of economy, the large-scale emergence of chemical enterprises results in the rapid increase in the types and mass concentration of pollutants in the atmospheric environment, and environmental quality has become a key issue for urban sustainable development that must be addressed as soon as possible (Mujtaba et al., 2016). According to the forecast data provided by the environmental management department, emergency measures may be taken to deal with heavy air pollution, such as strict control of motor vehicle exhaust emission, chemical enterprise discharge and construction dust emission (Pope and Wu, 2014; Merbitz et al., 2012). In addition, the technical support role of environmental prediction and analysis in environmental management is brought into full play to improve the quality of the atmospheric environment (Chattopadiay et al., 2010). The air quality prediction and evaluation model is an important technical method for atmospheric environmental quality detection. By establishing mathematical models of environmental pollutants under various topographical and meteorological conditions, it is possible to learn the physical and chemical mechanisms of transportation, diffusion, transformation and removal of pollutants in the atmospheric environment (Superczynski and Christopher, 2011; Zhan et al., 2018).

At present, the research of air quality evaluation model develops with the development of industrial society, and goes through the process of continuous improvement and development (Kumar et al., 2016; Vlachostas et al., 2010). In the air 
quality evaluation model, the atmospheric pollutant diffusion model is established by applying the meteorological principle to forecast the diffusion of environmental pollutants by means of computer technology in combination with the atmospheric dynamics principle, the atmospheric physics and the atmospheric chemistry application foundation (Elbir et al., 2010). The air quality assessment model is classified into local scale, urban scale and regional scale by simulation scale. In general, the urban scale is used for environmental quality prediction and evaluation (Barrile et al., 2018; Steve et al., 2008; Wang et al., 2015). Geographic information system (GIS) can manage spatial data by spatial location and study the interrelationship among various spatial entities. The GIS technology can visualize the air quality forecast data (Righini et al., 2014; Tirmizi and Tirmizi, 2018). In this paper, GIS technology is applied to the detection and evaluation of urban air quality and the spatial analysis ability of GIS technology is brought into full play to visually analyze the evaluation results so as to provide decision-making basis for air quality prediction.

\section{Materials and methods}

\section{Industrial sources, flow sources, and surface sources}

The establishment of an urban air pollution emission list is an effective tool for assessing urban air quality, which should specifically include emission source spatial location, emission data and emission parameters (Borrego et al., 2016; Siliello et al., 2014). There are three types of air pollution sources in urban areas: industrial, flow and surface sources (Carbajal-Hernández et al., 2012). Table 1 shows the source identification of the pollution sources. Except for the industrial sources where $\mathrm{O} 3$ comes from, the common atmospheric pollutants will be generated from the three major pollution sources. Relying on GIS technology, each pollution space is located by using longitude and latitude coordinate positioning method (Borbet et al., 2018). The industrial source estimation method includes the actual monitoring method, the emission factor method and the material balance method. The VOCs emission factor is generally determined with reference to the Atmospheric Volatile Organic Matter Source Emission Inventory issued by the State. The flow sources are mainly motor vehicle emissions, and the main emissions are VOCs and $\mathrm{NO}_{2}$. Surface sources include dust emission and combustion of domestic fuels, and surface sources of pollutant VOCs include vegetation, landfill sites and hospitals.

Table 1. Source identification of pollution sources

\begin{tabular}{c|c|c|c|c|c|c|c}
\hline \multirow{2}{*}{ Classification } & \multicolumn{7}{|c}{ Contaminant category } \\
\cline { 2 - 8 } & $\mathbf{P M}_{2.5}$ & $\mathbf{P M}_{\mathbf{1 0}}$ & $\mathbf{S O}_{2}$ & $\mathbf{N O}_{2}$ & $\mathbf{C O}$ & $\mathbf{V O C s}$ & $\mathbf{O}_{\mathbf{3}}$ \\
\hline Industrial source & $\sqrt{ }$ & $\sqrt{ }$ & $\sqrt{ }$ & $\sqrt{ }$ & $\sqrt{ }$ & $\sqrt{ }$ & $\sqrt{ }$ \\
Flow source & $\sqrt{ }$ & $\sqrt{ }$ & $\sqrt{ }$ & $\sqrt{ }$ & $\sqrt{ }$ & $\sqrt{ }$ & \\
Surface source & $\sqrt{ }$ & $\sqrt{ }$ & $\sqrt{ }$ & $\sqrt{ }$ & $\sqrt{ }$ & $\sqrt{ }$ & \\
\hline
\end{tabular}

\section{Uncertainty analysis of pollution sources}

Air quality is related not only to the spatial location and emission of emission sources, but also to meteorological conditions, including wind speed and wind direction. 
Figure 1 shows the monthly average wind speed monitored in Shijiazhuang City. It can be seen that Shijiazhuang City has the maximum average wind speed in March and the minimum average wind speed in October. Figure 2 shows the air pollution emission in downtown Shijiazhuang City. It can be seen that the surface source is the largest source of VOCs, with a sharing rate of over $63 \%$, and the industrial source is the primary source of $\mathrm{PM}_{10}, \mathrm{SO}_{2}, \mathrm{NO}_{\mathrm{x}}, \mathrm{CO}$ and $\mathrm{O}_{3}$. According to incomplete statistics, the total emission amount of VOCs in the central urban area of Shijiazhuang reached 31,101.36 $\mathrm{t}$ in 2017. Figure 3 shows the composition of urban atmospheric pollutant VOCs emission sources, vegetation, industrial and architectural ornaments are the three major sources of VOCs, accounting for $36.57 \%, 33.25 \%$ and $14.05 \%$ respectively. The quantitative estimation of VOCs pollutant emission source inventory is calculated by selecting representative emission factors and activity level data, which with greater uncertainties due to the instrument measurement, the representativeness of source test and random error.

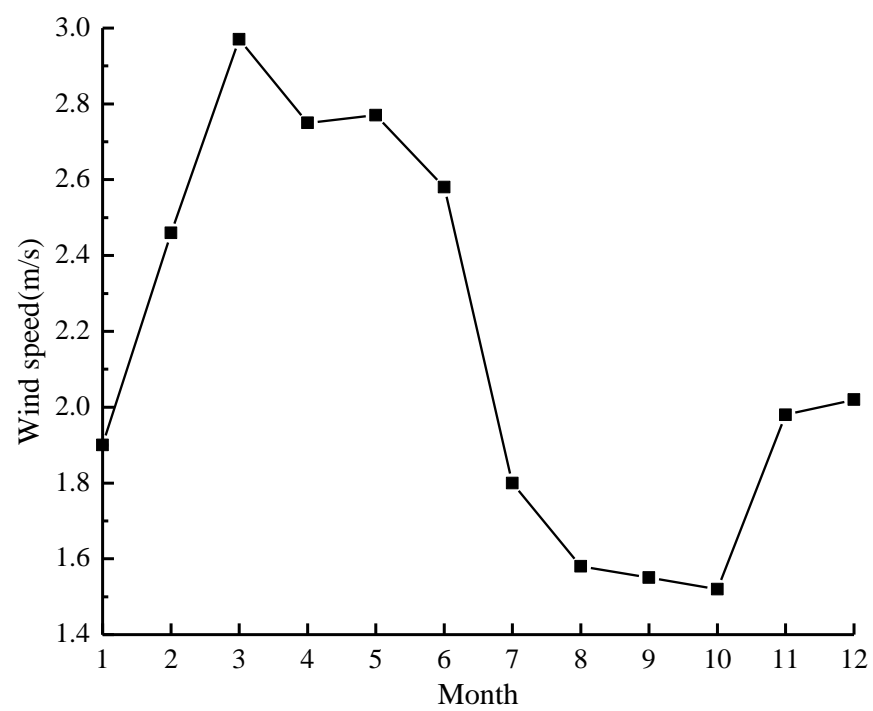

Figure 1. Shijiazhuang City monitors monthly average wind speed

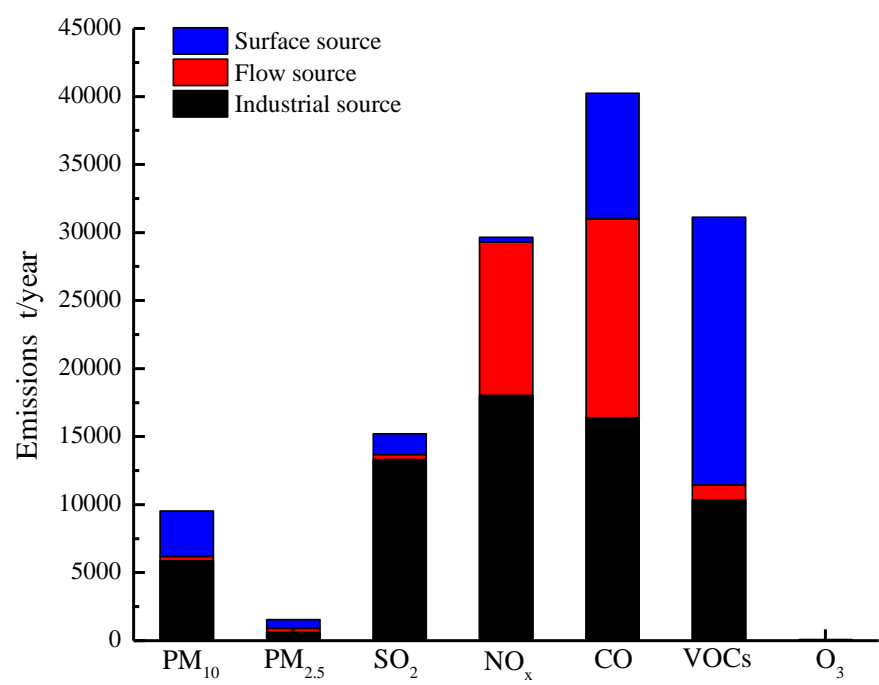

Figure 2. Air pollution emissions in downtown Shijiazhuang 


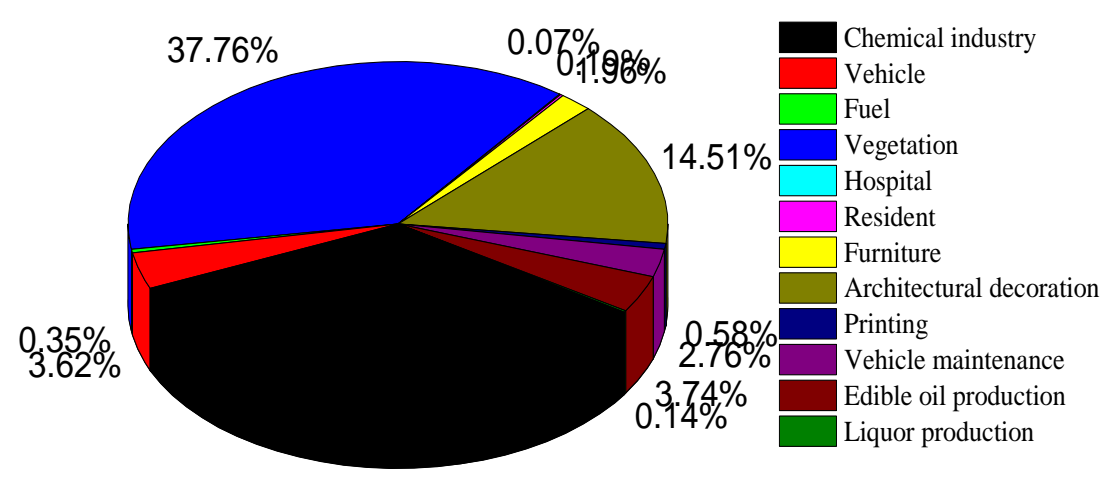

$34.33 \%$

Figure 3. Urban air pollutant VOCs emission source composition

\section{Results}

\section{Basic data required for the model operation}

AERMOD model is used to calculate the atmospheric pollutant concentration. When simulating the horizontal diffusion of industrial source plume pollutants, the mass concentration of grid coordinate point $(\mathrm{x}, \mathrm{y}, \mathrm{z})$ is assumed to be $\mathrm{c}(\mathrm{x}, \mathrm{y}, \mathrm{z})$ without considering the influence of topography. Considering the influence of the topography conditions, the total mass concentration of the grid point $\mathrm{c}(\mathrm{x}, \mathrm{y}, \mathrm{z})$ is shown in Equation 1:

$$
\mathrm{C}_{\mathrm{r}}(\mathrm{x}, \mathrm{y}, \mathrm{z})=\lambda \mathrm{c}(\mathrm{x}, \mathrm{y}, \mathrm{z})+(1-\theta) \mathrm{c}(\mathrm{x}, \mathrm{y}, \mathrm{z})
$$

where, $\theta$ represents the decomposition streamline height; $\lambda$ and $\theta$ represent the weight functions for horizontal and vertical point source diffusion states, respectively, as shown in Equations 2 and 3:

$$
\begin{aligned}
& \lambda=0.5(1+\xi) \\
& \xi=\frac{\int_{0}^{\mathrm{H}} \mathrm{C}(\mathrm{x}, \mathrm{y}, \mathrm{z}) \mathrm{d} \mathrm{Z}}{\int_{0}^{20} \mathrm{c}(\mathrm{x}, \mathrm{y}, \mathrm{z}) \mathrm{d} \mathrm{Z}}
\end{aligned}
$$

The basic data required for the model operation include pollution source parameters, meteorological data parameters, predicted point source coordinates, ground and highaltitude meteorological data. For industrial chimneys, the point source parameters include the height of the chimney, outlet inner diameter, discharge velocity and emission rate, while the surface source parameters include height, direction angle, length and emission rate.

\section{Model verification method}

For the convenience of simulation, the simulation results of atmospheric diffusion model are verified by using the developed AERMOD system, and necessary corrections are made to the model. The AERMOD model has been used by some scholars to verify the simulation results of $\mathrm{SO}_{2}$. The results show that the correlation coefficient between the monitored value and the simulated value of $\mathrm{SO}_{2}$ is 0.67 , which indicates that the 
AERMOD model has good applicability to the simulation of $\mathrm{SO}_{2}$ emissions. In addition, some researchers have applied the AERMOD model to the industrial point source pollutant emission area, which proved that the AERMOD model has good practicability in simulating pollution diffusion in the small and medium scale research area, and provides effective prediction data for air quality evaluation.

\section{Discussion}

\section{Model validation}

Table 2 is the emission list of pollution sources in downtown Shijiazhuang City. In selecting data of AERMOD model, it is necessary to add pollutants according to the factors of pollutants, and predict and simulate the residential areas, cultural areas and industrial areas in downtown Shijiazhuang City, with the secondary ambient air quality standard. The topographical parameters input in the AERMOD model include longitude and latitude coordinates and elevation, and the ground meteorological data include wind speed, wind direction, total cloud volume and dry-bulb temperature, where the wind direction, wind speed and dry-bulb temperature are the average value of observation data 24 times a day, and the total cloud volume is the average of 5 observations per day. Table 3 shows the location of project concerns for prediction. According to the requirements of environmental air quality monitoring and monitoring location, five representative concerns are set up in this study and the model is simulated for a total of 20 days.

Table 2. List of pollution sources in downtown Shijiazhuang

\begin{tabular}{c|c|c|c|c|c|c|c}
\hline \multirow{2}{*}{ Classification } & \multicolumn{7}{|c}{ Contaminant category } \\
\cline { 2 - 8 } & $\mathbf{P M}_{\mathbf{2 . 5}}$ & $\mathbf{P M}_{\mathbf{1 0}}$ & $\mathbf{S O}_{\mathbf{2}}$ & $\mathbf{N O}_{\mathbf{2}}$ & $\mathbf{C O}$ & $\mathbf{V O C s}$ & $\mathbf{O}_{\mathbf{3}}$ \\
\hline Industrial source & 5853.37 & 608.2 & 13309 & 18014.2 & 16372.20 & 10334.1 & 75.8 \\
Flow source & 323.88 & 292.0 & 377.86 & 11268.01 & 14612.88 & 1089.8 & \\
Surface source & 3330.04 & 630.15 & 1507.73 & 320.15 & 9204.15 & 19665.36 & \\
Total & 9507.29 & 1530.35 & 15194.59 & 29602.36 & 43189.23 & 31089.26 & 75.8 \\
\hline
\end{tabular}

Table 3. Forecast project focus location

\begin{tabular}{c|c|c|c}
\hline Concern point & \multicolumn{3}{|c}{ Position (m) } \\
\cline { 2 - 4 } & $\mathbf{X}$ & $\mathbf{Y}$ & Altitude \\
\hline Mine monitoring station & 6918.81 & -9254.65 & 65.91 \\
City No. 1 Middle School & 11038.22 & 4099.08 & 64.83 \\
Monitoring station & 11428.7 & 3151.55 & 67.03 \\
Daying Street monitoring station & 6773.08 & 1044.0 & 62.02 \\
Stylistic center monitoring station & 10975.48 & 754.73 & 67.45 \\
\hline
\end{tabular}

\section{Forecast results and analysis}

Figure 4 is a comparison between predicted results and monitoring results of VOCs of five concerns It can be seen that the predicted concentration values of VOCs in Shijiazhuang No. 1 High School are relatively high, while the predicted concentration 
values of monitoring station are relatively low, which is mainly because the selected monitoring station is located in the suburb of Shijiazhuang, and related to the coal or biomass fuel of the surrounding residents, the predicted values and monitoring values of the other three stations have the same trend. Table 4 is the predicted results of VOCs of five concerns, and Table 5 is the daily average predicted results of VOCs. The annual concentration of VOCs in Shijiazhuang City is predicted with the concern where the daily average concentration of VOCs is the highest among five concerns as the monitoring point. The concentration of VOCs predicted by AERMOD model is $0.1668 \mathrm{mg} / \mathrm{m}^{3}$, accounting for more than $110 \%$ of the standard rate, and appears in October in Shijiazhuang City, which is the month with the lowest wind speed.

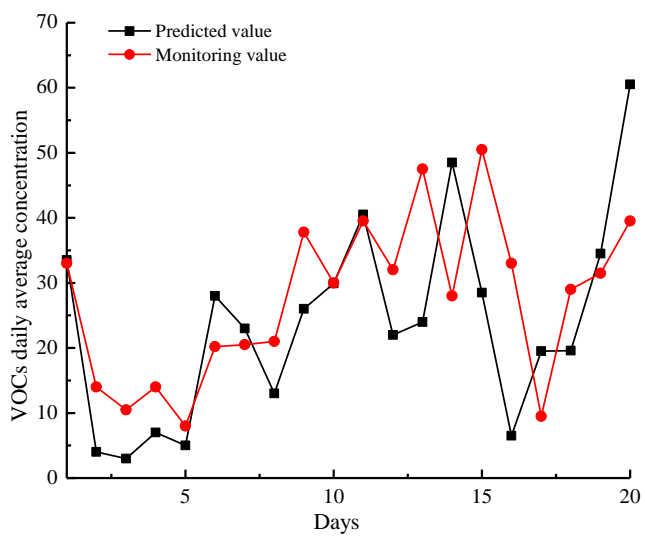

(a) Mine monitoring station

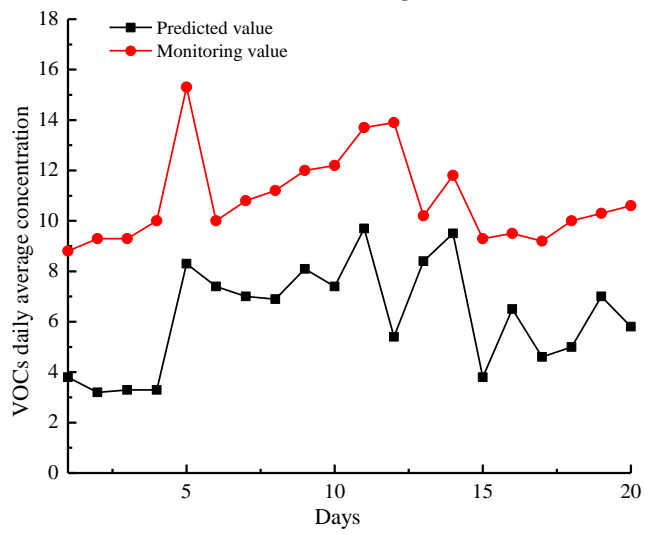

(c) Monitoring station

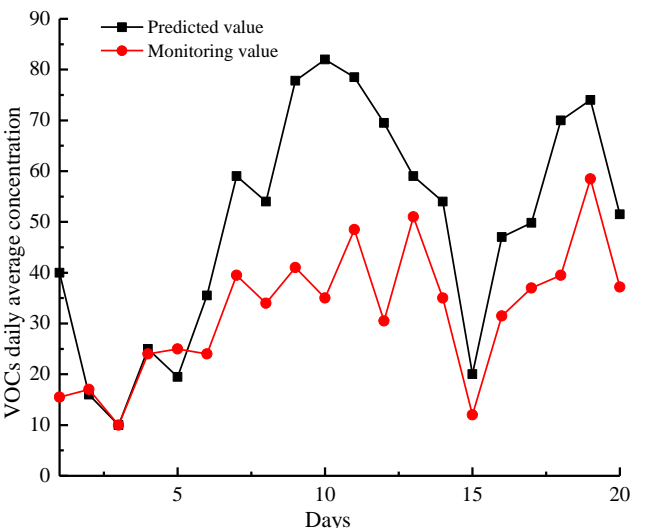

(b) Shijiazhuang City No. 1 High School

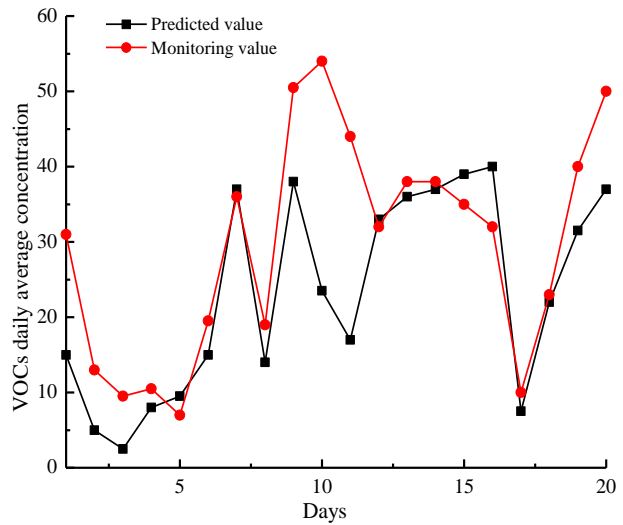

(d) Daying Street monitoring station

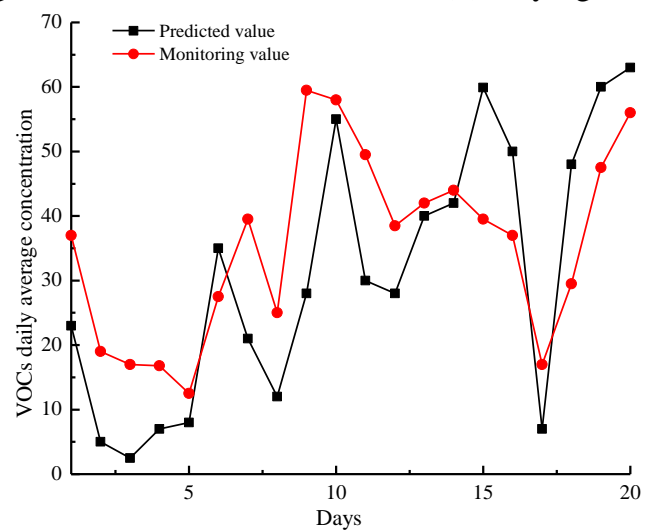

(e) Stylistic center monitoring station

Figure 4. Comparison of VOCs prediction results and monitoring results of five concerns 
Table 4. Five concerns VOCs prediction results $\left(\mu \mathrm{g} / \mathrm{m}^{3}\right)$

\begin{tabular}{c|c|c|c}
\hline \multirow{2}{*}{ Monitoring site location } & \multicolumn{3}{|c}{ VOCs } \\
\cline { 2 - 4 } & Predictive value & Monitoring value & Ratio \\
\hline Mine monitoring station & 37.38 & 28.85 & 1.296 \\
City No. 1 Middle School & 25.14 & 26.23 & 0.9586 \\
Monitoring station & 6.07 & 11.03 & 0.5506 \\
Daying Street monitoring station & 30.24 & 31.38 & 0.964 \\
Stylistic center monitoring station & 33.33 & 36.12 & 0.923 \\
Average & 26.432 & 26.722 & 0.990 \\
\hline
\end{tabular}

Table 5. Daily average forecast results of VOCs

\begin{tabular}{|c|c|c|c|c|c|c|}
\hline \multirow{2}{*}{ Focus point } & \multicolumn{3}{|c|}{ Position (m) } & \multirow{2}{*}{$\begin{array}{l}\text { Predictive } \\
\text { value }\end{array}$} & \multirow{2}{*}{$\begin{array}{l}\text { Standard } \\
\text { value }\end{array}$} & \multirow{2}{*}{$\begin{array}{c}\text { Occupancy } \\
\text { rate }(\%)\end{array}$} \\
\hline & $\mathbf{X}$ & $\mathbf{Y}$ & Altitude & & & \\
\hline $\begin{array}{l}\text { Mine monitoring } \\
\text { station }\end{array}$ & 6918.81 & -9254.65 & 65.91 & 0.171 & 0.152 & 112.5 \\
\hline $\begin{array}{c}\text { City No. } 1 \text { Middle } \\
\text { School }\end{array}$ & 11038.22 & 4099.08 & 64.83 & 0.011 & 0.152 & 7.24 \\
\hline Monitoring station & 11428.7 & 3151.55 & 67.03 & 0.079 & 0.152 & 51.97 \\
\hline $\begin{array}{c}\text { Daying Street } \\
\text { monitoring station }\end{array}$ & 6773.08 & 1044.0 & 62.02 & 0.015 & 0.152 & 9.87 \\
\hline $\begin{array}{c}\text { Stylistic center } \\
\text { monitoring station }\end{array}$ & 10975.48 & 754.73 & 67.45 & 0.143 & 0.152 & 94.08 \\
\hline
\end{tabular}

\section{Conclusions}

In this paper, GIS technology is applied to the detection and evaluation of urban air quality, and the spatial analysis ability of GIS technology is brought into full play to visually analyze the evaluation results. The concrete conclusions are as follows:

(1) The surface source is the largest source of VOCs, with a sharing rate of over $63 \%$, and vegetation, industrial and architectural ornaments are the three major sources of VOCs, accounting for $36.57 \%, 33.25 \%$ and $14.05 \%$ respectively.

(2) The basic data required for the AERMOD model operation include pollution source parameters, meteorological data parameters, predicted point source coordinates, ground and high-altitude meteorological data. The research indicates that the AERMOD model has good applicability to the simulation of SO2 emissions.

(3) The comparison between predicted results and monitoring results of VOCs of five concerns in Shijiazhuang City shows that the predicted concentration values of VOCs in Shijiazhuang No. 1 High School are relatively high, while the predicted concentration values of monitoring station are relatively low, and the predicted values and monitoring values of the other three stations have the same trend.

(4) Here only considers the impact of multiple point sources on the concentration of VOCs in Shijiazhuang City. The follow-up study can be made with additional pollution sources such as linear and surface sources to more roundly evaluate urban air quality. 
Acknowledgements. Henan Science and Technology Project "Study on Biological Toxicity of Water Quality in Henan Province" (No. 152102310343). Research Start up Fund of North China university of Water Resources and Electric Power (No: 201621).

\section{REFERENCES}

[1] Barrile, V., Fotia, A., Bilotta, G. (2018): Geodatabase for the assessment of energetic potential of territory. - Ingénierie des Systèmes d'Information 23(6): 7-17.

[2] Borbet, T. C., Gladson, L. A., Cromar, K. R. (2018): Assessing air quality index awareness and use in Mexico City. - BMC Public Health 18(1): 538.

[3] Borrego, C., Costa, A. M., Ginja, J., Amorim, M., Coutinho, M., Karatzas, K. D., Sioumis, T., Katsifarakis, N., Konstantinidis, K., Vito, S. D., Esposito, E., Smith, P. D., André, N., Gérard, P., Francis, L. A., Castell, N., Schneider, P., Viana, M., Minguillón, M. C., Reimringer, W., Otjes, R., Sicard, V. O., Pohle, R., Elen, B., Suriano, D., Pfister, V., Prato, M., Dipinto, S., Penza, M. (2016): Assessment of air quality microsensors versus reference methods: the Eunetair joint exercise. - Atmospheric Environment 147: 246-263.

[4] Carbajal-Hernández, J. J., Sánchez-Fernández, L. P., Carrasco-Ochoa, J. A., MartínezTrinidad, J. F. (2012): Assessment and prediction of air quality using fuzzy logic and autoregressive models. - Atmospheric Environment 60(6): 37-50.

[5] Chattopadhyay, S., Gupta, S., Saha, R. N. (2010): Spatial and temporal variation of urban air quality: a GIS approach. - Journal of Environmental Protection 1(3): 264-277.

[6] Cinderby, S., Snell, C., Forrester, J. (2008): Participatory GIS and its application in governance: the example of air quality and the implications for noise pollution. - Local Environment 13(4): 309-320.

[7] Elbir, T., Mangir, N., Kara, M., Simsir, S., Eren, T., Ozdemir, S. (2010): Development of a GIS-based decision support system for urban air quality management in the city of istanbul. - Atmospheric Environment 44(4): 441-454.

[8] Kumar, A., Gupta, I., Brandt, J., Kumar, R., Dikshit, A. K., Patil, R. S. (2016): Air quality mapping using GIS and economic evaluation of health impact for Mumbai city, India. - Journal of the Air \& Waste Management Association 66(5): 470-481.

[9] Merbitz, H., Buttstädt, M., Michael, S., Dott, W., Schneider, C. (2012): GIS-based identification of spatial variables enhancing heat and poor air quality in urban areas. Applied Geography 33(1): 94-106.

[10] Mujtaba, S. M., Husain, T., Alharbi, B. (2016): Optimization of air quality monitoring network using GIS based interpolation techniques. - Journal of Environmental Protection 7(6): 895-911.

[11] Pope, R., Wu, J. (2014): A multi-objective assessment of an air quality monitoring network using environmental, economic, and social indicators and GIS-based models. Journal of the Air \& Waste Management Association 64(6): 721-737.

[12] Righini, G., Cappelletti, A., Ciucci, A., Cremona, G., Piersanti, A., Vitali, L. (2014): GIS based assessment of the spatial representativeness of air quality monitoring stations using pollutant emissions data. - Atmospheric Environment 97: 121-129.

[13] Silibello, C., Bolignano, A., Sozzi, R., Gariazzo, C. (2014): Application of a chemical transport model and optimized data assimilation methods to improve air quality assessment. - Air Quality Atmosphere \& Health 7(3): 283-296.

[14] Superczynski, S. D., Christopher, S. A. (2011): Exploring land use and land cover effects on air quality in central Alabama using GIS and remote sensing. - Remote Sensing 3(12): 2552-2567.

[15] Tirmizi, S. T., Tirmizi, S. R. U. H. (2018): GIS based risk assessment of oil spill and gas leakage vulnerable zones in Pakistan. - Mathematical Modelling of Engineering Problems 5(3): 190-196. 
[16] Vlachokostas, C., Nastis, S. A., Achillas, C., Kalogeropoulos, K., Karmiris, I., Moussiopoulos, N. (2010): Economic damages of ozone air pollution to crops using combined air quality and GIS modelling. - Atmospheric Environment 44(28): 3352-3361.

[17] Wang, W., Ying, Y., Wu, Q., Zhang, H., Ma, D., Xiao, W. (2015): A GIS-based spatial correlation analysis for ambient air pollution and AECOPD hospitalizations in Jinan, China. - Respiratory Medicine 109(3): 372-378.

[18] Zhan, N. Y., Gao, Z., Deng, Y. F. (2018): Diffusion of vehicle exhaust pollutants in typical street canyons. - International Journal of Heat and Technology 36(3): 835-839. 